\title{
UNDERSTANDING THE INCREASED FRUIT CONTENT OF SOLUBLE PROTEINS, SUGARS, CERTAIN ENZYME ACTIVITIES, AND CERTAIN POLYPHENOLS IN CONTEXT TO DATE FRUIT RIPENING
}

\author{
Saad Salman M. Alqarni ${ }^{1}$, Mohammad D. Bazzi ${ }^{2}$ \\ ${ }^{1}$ Department of Basic Sciences, College of Science and Health Professions, King Saud bin Abdulaziz \\ University for Health Sciences (KSAU-HS) \\ ${ }^{2}$ Department of Biochemistry, College of Science, King Saud University, Riyadh, Saudi Arabia.
}

\begin{abstract}
Introduction: To understand the increased fruit content of soluble proteins, sugars, certain enzymes activities, and certain polyphenols in context to date fruit ripening. Materials and Methods: The study collected four varieties of date fruits from a farm in Riyadh, Saudi Arabia. In it, 10-14-day intervals separated the various stages of maturity. The process of sample preparation and extraction includes the samples of fruits at different stages of maturation. Results and Discussion: The Polyphenols oxidize activity appeared to decline with further maturation of date fruit. There was an increase in the protein content and the reducing sugar in all varieties of dates. The changes in the total sugar and reducing sugar occurred due to the increased enzyme's activity. Conclusion: The reducing sugar increased in all varieties of the date fruit. The coordination of the enzyme might influence the quality of the ripening of date fruits.
\end{abstract}

Keywords: Dates, Ripening, Enzymes, Fruit.

*Corresponding author:

King Saud bin Abdulaziz University for Health Sciences (KSAU-HS), Riyadh, Kingdom of Saudi Arabia.

E-mail. alqarnisa@ksau-hs.edu.sa, alqarnis@gmail.com

\section{Introduction}

Date palm is recognized as the staple food crop for the Middle East, enabling food supply for people for about 5000 years especially to those living in the Kingdom of Saudi Arabia (Aleid, Al-Khayri, \& Al-Bahrany, 2015). Commonly known as Phoenix dactyliferaL (family Arecaceae), date fruit is a food product that is highly rich in calories, minerals, and many vitamins. The content of date fruit is composed of about eighty percent of the sugar while the remainder consists of fat, minerals and protein products (Nestle, 2013). It serves as a staple fruit item for the people suffering from hypertension based on extremely low sodium content and exceptionally rich in potassium (Sirisena, Ng, \& Ajlouni, 2015). Along with this, the fruit consists of a large amount of hemicellulose and cellulose materials that are compulsory for the maintenance of intestinal motility. Apart from promoting the formation of blood (Das, 2015), the date fruit also enjoys the status of being easily digestible food with many health benefits.

The amount of dietary fibers in date fruits ranges from 6.5 percent to 11.5 percent, where remaining content comprises of 1 percent fat, two percent ash, and two percent protein, and is a primary source for phenolic antioxidants (Ghnimi et al., 2017). The nutritional value of the date fruit is affected by its chemical composition variations, along with its quality sensor and industrial consumption (Mrabet et al., 2012). Fruit softening is termed as the primary determiner of the fruit quality which also impacts the cell wall degradation triggered by enzyme (Rastegar et al., 2015). Among the development procedure, ripening is the final phase of the fruits that intrinsically affects the quality distinctiveness appearance of the fruit. The chemical composition of the date fruit goes under high chemical and physical variation given its formation and ripening stage. The fruit passes through four different 
stages distinguishable by changes in one or more particular characteristics. Four Arabic terms are used for the development stages of date fruits; namely, Kimri that refers to the phase when the dates are green in color and young. At this stage, there is a rapid increase in size, weight, and reducing sugars; it is the period of highest acid activity and moisture content (up to 85\%). The development of date fruit in the second phase, Khalal also known as Bisr, is reached when dates reach to the maximum size and weight and begin to change in color and may turn into yellow, yellowscarlet, red pink or yellow spotted with red depending on the variety of dates. At this stage, weight gain is slow; whereas, sucrose content increases, moisture content declines, and tannins precipitates and lose its astringency. The development of date fruit in the third stage appears when the date fruit loses their astringency and initiation of acquiring a darker and less attractive color begins, indicating towards the third phase known as Rutab. The Rutab stage is the one when the tips of the fruit start to turn brown. The fourth and the final stage of the date fruit development is Tamar stage when fruit becomes completely solid and brownish. Climatic conditions make the dates ripen further and turn into Tamar, which is characterized by darker colors, and such low moisture content date becomes self-preserving (Shamim et al., 2013).

The ripening of date fruits brings changes to the fruits including variations in the sugar content, aroma, and flavors, production of color compounds, and also the softening of cell walls. The softening of the date fruit is linked with the ripening process of many fruits and is attributed to the degradation of cell-wall polysaccharides (Terasaki et al., 2013). Not only this, various studied have claimed date fruit, in general, contains antimutagenic and antioxidant properties (Al-Jasass, Siddiq, \& Sogi, 2015). Recent paperwork on dates has emphasized the exploration of the health benefits associated with the date fruit and date pits along with their utilization of functional component for the development of numerous value-added products of food as well as its supplements (Amira et al., 2012). The date fruit market accounts to 7.2 million $\mathrm{mt}$ globally which is further expected to increase, emphasizing towards the exploration of its content and its associated developmental stages (Haider et al., 2014. Consequently, the objective of this study is to examine the overall composition of date fruit as well as its ripening stages.

\section{Enzymes in Date Fruit Ripening Processes}

In this study, the focus is on the date fruit changes in the activity of amylase, pectinase, cellulase, and polyphenol oxidase (PPO) that undergoes the various stages of maturity. These enzymes are often involved in changes in the four significant attributes of fruit during ripening: color, taste, aroma, and texture. Four different varieties of dates were examined to test the universality of these enzymes in date fruit ripening processes.

Pectinase is a term that refers to a mixture of enzymes that includes polygalacturonases, pectin, and pectin lyases. This enzyme is helpful during the natural ripening procedure of fruits and plays a significant part in cell wall metabolism during the ripening process. The softening and remodeling of the walls of cells during the development and growth could be more accessible due to continued activity of these enzymes together with other enzymes.

Previous work by Rastegar et al (2012) has declared that ripening of the date fruits involves other enzymes as well like cellulase, invertase, pectinesterase, and polyphenol oxidases. Saleem et al (2005) coordinated actions of all the enzymes are observed as a dependable factor for converting Rutab into Tamar with all its associated manifestations in the characteristics such as sweeter taste, softening of structuring, and changes in the colors of fruits and the precipitations of tannins and other ripening-associated quality parameters.

Another vital enzyme is amylases that are revealed as a group of enzymes hydrolyzing starch, which is the most common digestible polysaccharide, found in foods (Sahni \& Goel, 2015). Starch granules are relatively resistant to penetration by both hydrolytic enzymes and water due to the development of intra- and intermolecular hydrogen bonds. Their digestion occurs before starches enter or leave the cell (Agudelo et al., 2014). Amylases are synthesized during the ripening process in many plants and fruits making them sweeter. These are the heterogeneous groups of enzymes that catalyze the hydrolysis of $\alpha-1,4$ glycosidic bonds of polysaccharides to yield 
dextrin, oligosaccharides, maltose, and Dglucose (Li et al., 2016).

There are a group of enzymes called cellulose, which shows increased activity during the process of fruits ripening. The activity of certain enzymes is found to result in apoptosis, the disintegration of the walls of the cells and also in the softening of the fruits (Tucker \& Grierson, 2013). There are many significant roles of pigments in the ripening process of date fruits. The formation of different colors during the process of ripening might be the result of pigments breakdown or due to the synthesis of new ones (Mou et al., 2015). The primary purpose of conducting the research was to understand the increased fruit content of soluble proteins, sugars, specific enzymes activities, and certain polyphenols in context to date fruit ripening.

\section{Materials and Methods}

\section{Sample Collection and Storage Procedure}

The study collected the date fruits at various stages of ripening from four different date palm varieties (Sukkari, Hilwa, Sullaj, and Khalas) part of a private farm in Riyadh, Saudi Arabia. Ten different sets of samples representing ten different stages of maturity for each date fruit variety was examined. Fruit maturity stages were separated by $10-14$ days intervals (Table 1).

Table 1: Time for Date Fruit Sample Collection

\begin{tabular}{|l|l|l|l|l|}
\hline Dates & Sukkari & Hilwa & Sullaj & Khalas \\
\hline May & 19 & - & $\begin{array}{l}6,16, \\
30\end{array}$ & 16,30 \\
\hline June & 14,24 & $\begin{array}{l}2,14, \\
24\end{array}$ & 14,23 & 14,23 \\
\hline July & $\begin{array}{l}3, \quad 18, \\
27\end{array}$ & $\begin{array}{l}3,18, \\
27\end{array}$ & $\begin{array}{l}3,17, \\
27\end{array}$ & $\begin{array}{l}3, \quad 17 \\
27\end{array}$ \\
\hline August & 10,25 & 10,25 & 10,25 & 10,25, \\
\hline September & $8,23$. & 8 & - & 7 \\
\hline
\end{tabular}

For each variety, all samples were collected from the same tree to minimize variations among the representatives of this variety.

The powder homogenate was centrifuged at $15,000 x g$ in a Beckman J-20 centrifuge at $4^{\circ} \mathrm{C}$ for $15 \mathrm{~min}$. The study used supernatant for the various biochemical parameters mentioned above (content of soluble proteins, sugars, certain enzymes activities, and polyphenols). It extracted $1 \mathrm{~g}$ (wet-weight) date with $3 \mathrm{~mL}$ buffer for all samples of this study. The process of sample preparation and extraction includes the samples of fruits at different stages of maturation and the samples were rinsed with distilled water and divided into two parts. A buffer containing $50 \mathrm{mM}$ sodium acetate $(\mathrm{pH} 5.0)$ and $100 \mathrm{mM} \mathrm{NaCl}$ was used for extraction of the data. Whereas, extraction of the second sample occurred with methanol to determine the sample's content of pigments. The purpose of determining the content of reducing sugars, total sugars, protein and various enzymes activities of the sample. The calculation for the concentration of reducing sugars in samples was held from a standard glucose curve prepared under the same conditions, except that $1 \mathrm{~mL}$ samples containing $0,0.2,0.5,1.0,2.0,3.0-$ or $5.0-\mathrm{mM}$ glucose was used. Reducing sugar in date fruit extracts was determined using the same procedure. Due to the high sugar content of most samples, it was necessary to dilute all extracts $(1.250 \mathrm{ml})$ before sugar determination. The equivalence reporting was found for reducing the sugar content of as equivalent glucose concentration.

\section{Preparation of Crude Extract}

Fruit samples were cut into pieces and weighed after the removal of and mashed with methanol (99.8\%). Throughout this research, the study used a ratio of $5 \mathrm{~mL}$ methanol perl $\mathrm{g}$ date. After maceration, the extract was centrifuged at $15,000 \times \mathrm{xg}$ in a Beckman J-20 centrifuge at $4{ }^{\circ} \mathrm{C}$ for $15 \mathrm{~min}$. Total sugar was determined using the anthrone reagent (97\%), and in this assay, hydrolyzation was used to convert carbohydrates into simple sugars, which then are converted into refural derivatives that interact with anthrone to form a blue-green complex. The concentration of total sugar was determined using glucose as a reference sugar. A standard curve was prepared using $250 \mu \mathrm{l}$ samples containing 0 , $0.2,0.4,0.6,0.8,1$, or $2 \mathrm{mM}$ glucose.

Reducing sugar content was determined by using dinitrosalicylic acid (DNS). This method tests for the presence of free carbonyl group in sugars $(\mathrm{C}=\mathrm{O}$, or the so-called reducing sugars $)$. The reaction involves the oxidation of the 
aldehyde functional group present in sugars with simultaneous reduction of 3, 5dinitrosalicylic acid (DNS) to 3-amino, and 5nitrosalicylic acid under alkaline conditions. Standard glucose curve prepared under the same conditions was used for determining the concentration of reducing sugars in samples, except that $1 \mathrm{~mL}$ samples containing $0,0.2$, $0.5,1.0,2.0,3.0-$ or $5.0-\mathrm{mM}$ glucose was used. Under these conditions, the absorbance at 540 $\mathrm{nm}$ was linear with glucose concentration in the range $0-5 \mathrm{mM}$.

The protein content of samples was calculated from a standard curve using bovine serum albumin (BSA) as a reference. $200 \mu \mathrm{l}$ samples containing $0.0-25 \mu \mathrm{g}$ BSA were used, and the absorbance at $595 \mathrm{~nm}$ was plotted against known concentrations of BSA Extractions of the sukkari samples were also carried out with a buffer containing $0.5 \%$ nonidet (a detergent) to increase the extraction power of the buffer. However, the results showed that the presence of this detergent had little impact on all parameters tested, and subsequently, was eliminated from all extraction procedures.

\section{Results}

\section{Sukkari}

The results have shown major changes during the process of ripening, and it was a result of synthesis pathways (proteins, sugars, etc.) as well as the degradation pathways (Pigments, certain enzymatic activities). Changes in different parameters were superimposed in order to gain a better insight into these processes. Figure 1 compares the variations in reducing sugars, total sugars, and proteins in sukkari fruit ripening. It has been observed that all three contents appeared to change in simultaneous trends. The changes in total sugar come out to precede changes in reducing sugar. This result has suggested that synthesis of the non-reducing agents most probably sucrose preceded the synthesis of reducing sugars specifically to fructose and glucose. It is possible that there was a transient induction of invertase in sukkari fruit, an enzyme that converts the sucrose into glucose and fructose.

The changes in total sugars or the reducing sugars might occur as a result of the increased activity of enzymes responsible for the hydrolysis of starch into simple sugars. There is a transient change in the activity of amylases concurrent with the increase in the content of reducing the sugar content of sukkari. At the latter stages, there was a decline observed in the process of ripening accompanied by the modest increases in reducing the sugar content of sukkari.

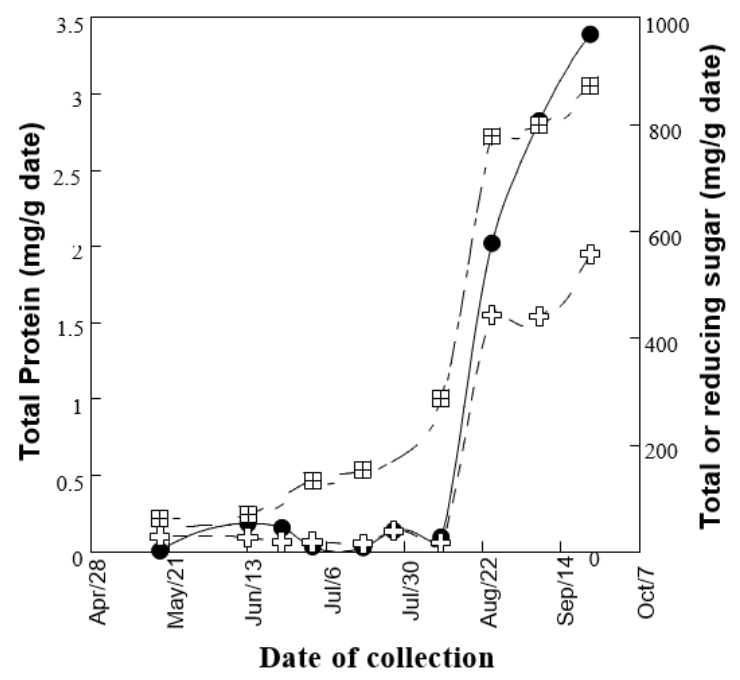

Figure 1. Total Sugars, reducing Sugars and Soluble Proteins of Sukkari during Ripening. The figure defines the changes in the total soluble content $(\bullet)$ during Sukkari Ripening Stages.

The superimposition activity of PPO, amylase, and pectinase can be observed in figure 2. The activity of pectinase can be observed fluctuating during the process of ripening. Whereas, amylase and PPO have shown a sudden burst of activities during the last stages of ripening process followed by an abrupt decline. PPO has been reported as a major player in the ripening process of sukkari fruit.

Other date fruit types (hilwa, sullaj, and khalas) indicated similar biochemical changes of sukkari date as shown in figure 2. Figures have shown the results for all types of dates including hilwa, sukkari, sullaj and khalas.

\section{Hilwa}

Figure 3 has shown that hilwa date has low levels of protein during the process of ripening at early stages, but its protein content has been observed to substantially increase during the rutab stage and reached a maximum at the Tamar stage. At the last stage of the ripening 
process, a slight decrease in the protein content was observed. This decrease might be attributed to the breakdown of the proteins, normally observed during senescence of fruits. The highest protein content observed was 1.7 $\mathrm{mg} / \mathrm{g}$ date recorded for samples collected on the 25th of August.

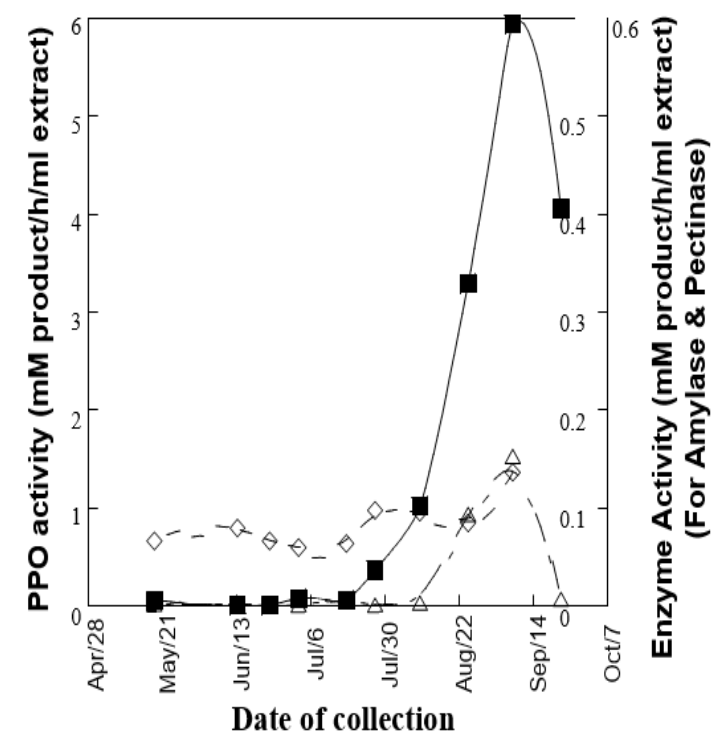

Figure 2. Changes in Enzymatic Activities of Sukkari during Ripening. This figure contrasts the change in enzymatic activities of amylase $(\Delta)$, Pectinase $(\diamond)$, polyphenol oxidase $(\mathbf{\square})$ during ripening of sukkari date fruit. The scale on the left is applicable to PPO activity only.

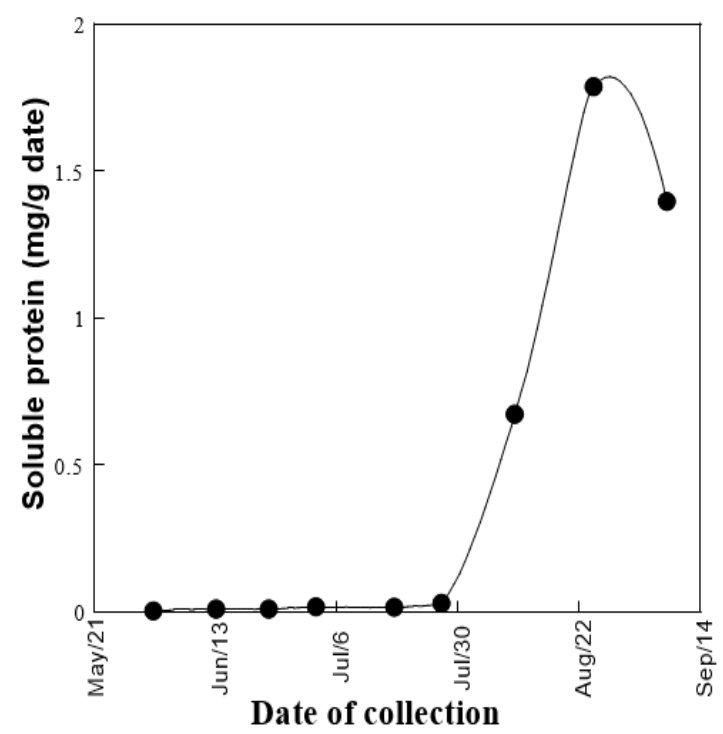

Figure 3. Soluble Protein of Hilwa Fruit during various Stages of Ripening. This figure contrasts the change in soluble protein $(\bullet)$ during the ripening of sukkari date fruit.
The results also showed that hilwa fruit had modest levels of sugar at the early stages of ripening $(73 \mathrm{mg} / \mathrm{g}$ date or about $7 \%$ by weight for June through July 18; Figure 4). Highest total sugar content was $782 \mathrm{mg} / \mathrm{g}$ date or about $78 \%$ of date fruit by weight at the Tamar stage in Hilwa date.

Variations in the reducing sugars content of hilwa paralleled that of total sugars; the lowest reducing sugar content $(40 \mathrm{mg} / \mathrm{g}$ date or about $4 \%$ by weight) was recorded at first stages of ripening. The later stages of ripening exhibited dramatic increases in reducing sugar content. The highest content $(654 \mathrm{mg} / \mathrm{g}$ date or $65 \%$ by weight) was recorded for samples collected on the eighth of September when the fruits were fully ripened (Figure 4).

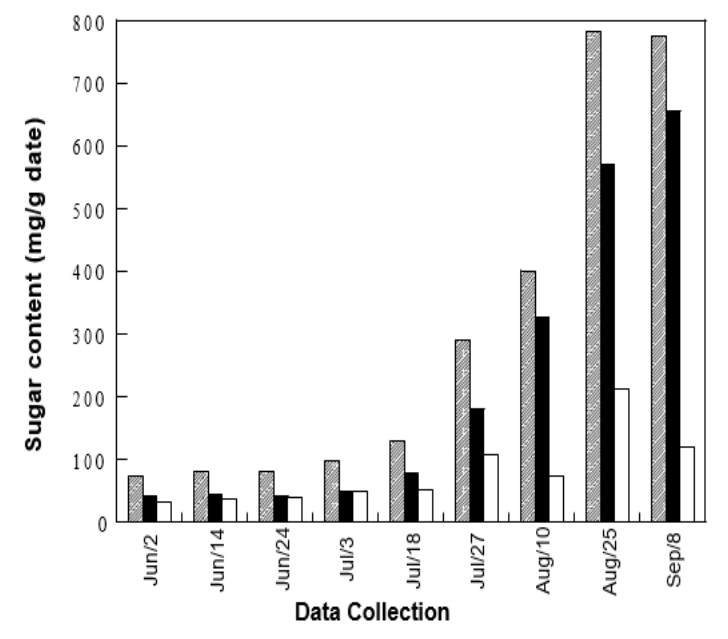

Figure 4. Sugar Content of Hilwa Date Fruit during Ripening Stages (The results show changes in total sugar (hatched bars), reducing sugars (solid bars), and non- reducing sugars (open bars).

The results have shown that the PPO activity appeared to decline with further maturation of date fruit, possibly the result of the accumulation of polyphenolic compounds (Figure 5). It has been observed from the results that hilwa fruit underwent major changes during ripening. Ripening increased the soluble proteins, total sugars and reducing sugars. The comparison between the concurrent trends can be observed through figure 6 , representing the various stages of ripening were extracted with a buffer containing $50 \mathrm{mM}$ sodium acetate $(\mathrm{pH}=5.0)$ and $100 \mathrm{mM} \mathrm{NaCl}$. The Protein content of each extract was determined using the 
Bradford method as described in the method section. All measurements were performed in duplicates.

It has been observed from the results that the increase in reducing sugars content of hilwa was probably the result of increased activity of hydrolysis enzymes that convert polysaccharide into simple sugars.

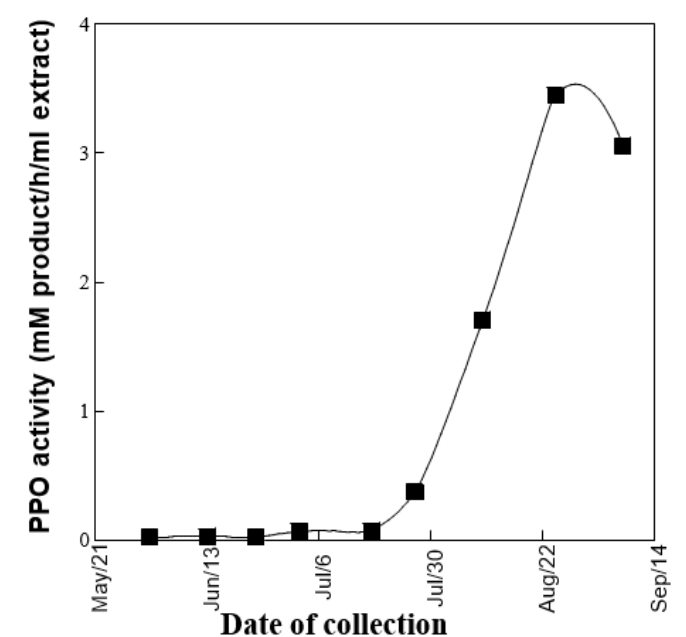

Figure 5. PPO Activity at Various Stages of Hilwa Ripening. This figure contrasts the change in polyphenol oxidase (ロ) during ripening of Hilwa date fruit.

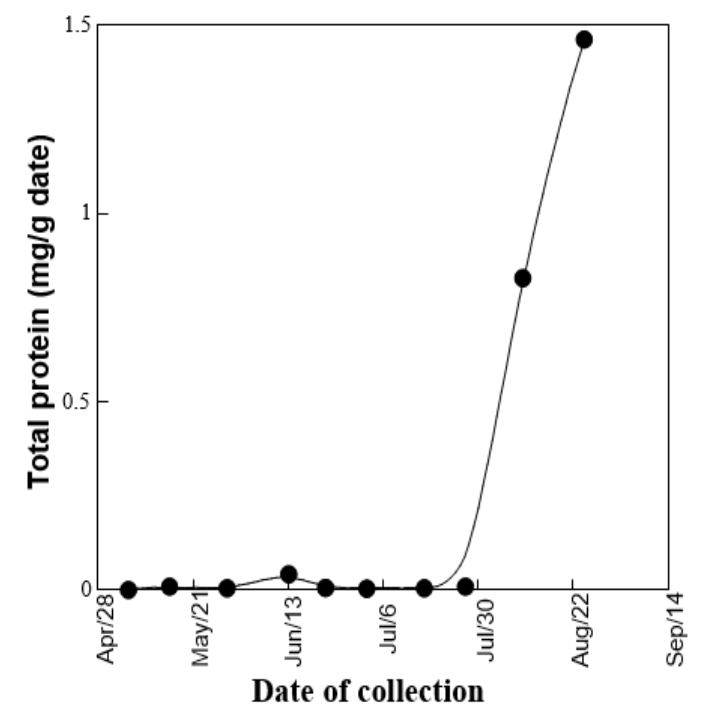

Figure 6. Soluble Protein Content $(\bullet)$ of Sullaj Fruit at the Various Stages of Ripening

\section{Sullaj}

The results from figure 6 have shown the soluble protein content of sukkari fruit at the various stages of ripening of the sullaj fruit during different phases of the ripening process.
At the early stages of the ripening process, the protein content has been observed relatively low. However, the protein content of sullaj fruit has been observed to increase dramatically as the fruit entered the Tamar stage. The PPO activity of sullaj extracts showed definitive, but low levels of PPO activity during the first stages of ripening.

The changes have been observed in the reducing sugars and total sugars, and this might be the result of increased enzymes, which was responsible for starch hydrolysis into simple sugars. The results have also reported that the increase in amylase activity in sullaj was concurrent with the increase in reducing sugar content (Figure 7).

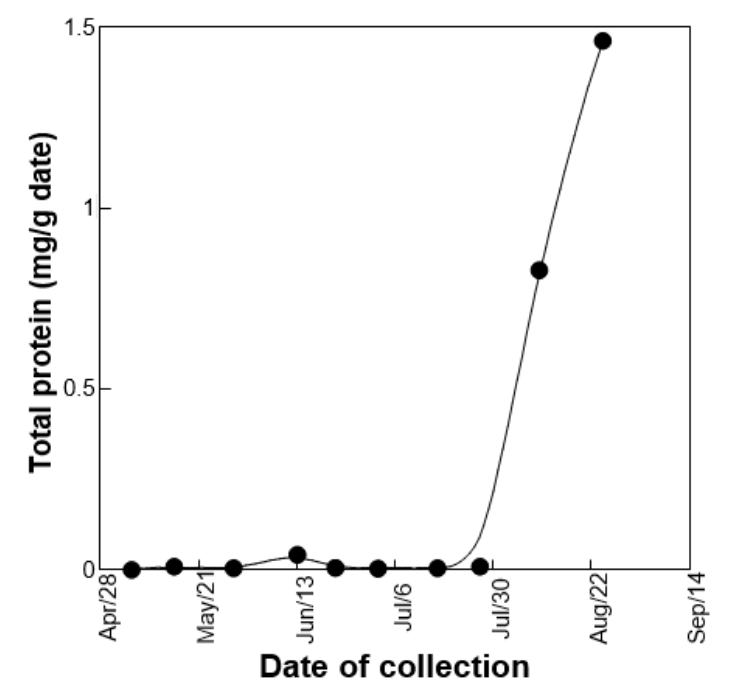

Figure 7: Soluble protein content of Sullaj fruit at the various stages of ripening. Samples representing the various stages of ripening were extracted with a buffer containing $50 \mathrm{mM}$ sodium acetate $(\mathrm{pH} 5.0)$ and $100 \mathrm{mM} \mathrm{NaCl}$.

The changes in total sugars come out to make changes in reducing sugars, which in turn preceded changes in protein content; this suggested that the synthesis of non-reducing sugar preceded the synthesis of reducing sugar. There might be an independent occurrence of the non-reducing sugar via different pathways or enzymes. There was a transient induction of intervase in sullaj that converts sucrose into fructose and glucose due to the decline in the sugar content at the final ripening stage.

\section{Khalas}

The results have reported that the transient increase in the amylase activity was concurrent with the increase in reducing the sugar content 
of khalas. Moreover, the decrease of amylase activity at the latter stages of ripening was accompanied by a decrease in reducing sugars content of khalas. Figure 8 has explained the transition of color to show the increase in PPO activity. The color turned from yellow to light brown due to the enzyme activity, and it might oxidize many phenolic compounds with subsequent generation of darker colors.

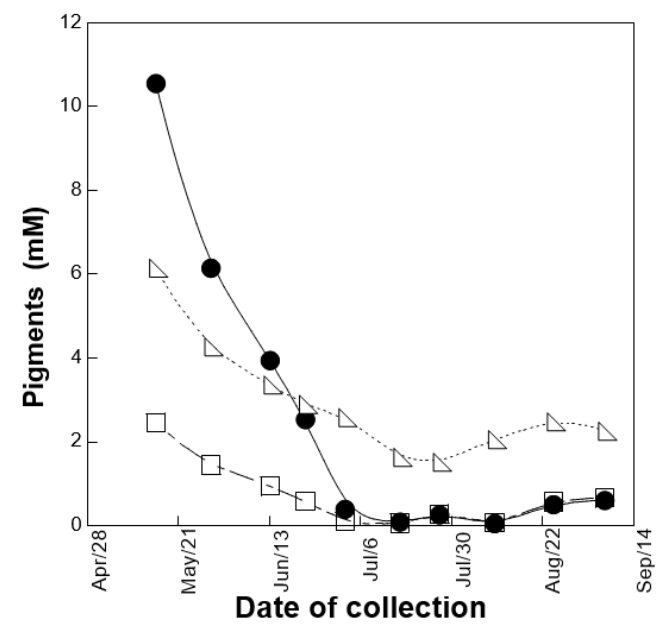

Figure 8. Changes in Enzymatic Activities of Khalas during Ripening. This figure contrasts the change in enzymatic activities of amylase $(\Delta)$, Pectinase $(\diamond)$, soluble protein $(\bullet)$ during ripening of Khalas date fruit.

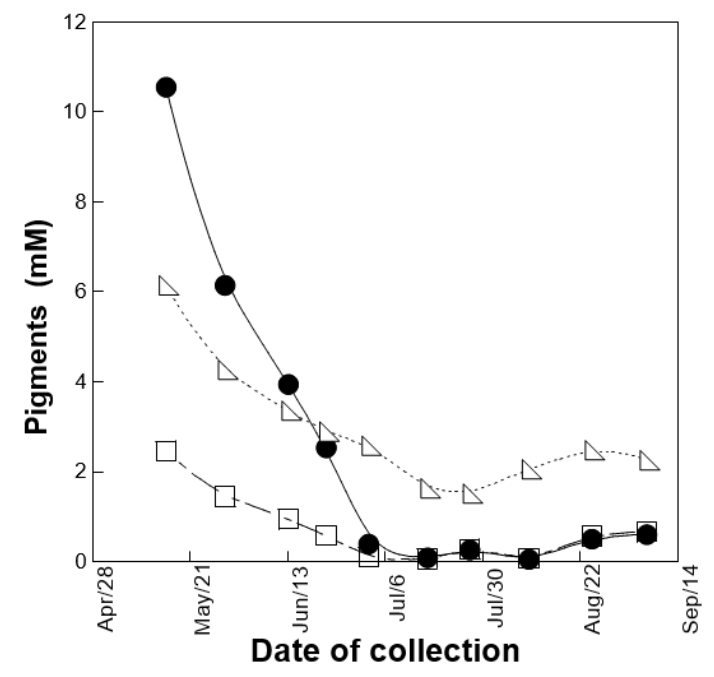

Figure 9: Chlorophylls and carotenoids content of Khalas during ripening. The concentrations of chlorophyll a $(\bullet) \&$ chlorophyll b ( $\square$ ) as well as carotenes $(\Delta)$ in the extracts of Khalas were estimated from absorption spectra via empirical formulas given in the method's section.
There are many interesting similarities and differences among different varieties of dates. In all varieties of dates, there is increased sugar content, protein content, certain enzymes activities and synthesis of certain phenols. The ripening process also involved many catabolic changes such as degradation of chlorophylls, carotenes, and other pigments (Figure 9).

An important characteristic of all varieties of date has been explored by examining the protein content. It has been observed that the protein content occurred in all varieties of dates during July. The major increase in the protein content was first observed in khalas, but all the changes in the types of dates occurred in a narrow frame of time. This has suggested that the temperature of the season might have an effective role in protein induction. The protein content in other varieties of dates also continued to increase the protein content with the process of ripening except for hilwa variety that showed a slight but significant decrease in the protein content at the final stage of the ripening process (Figure 10).

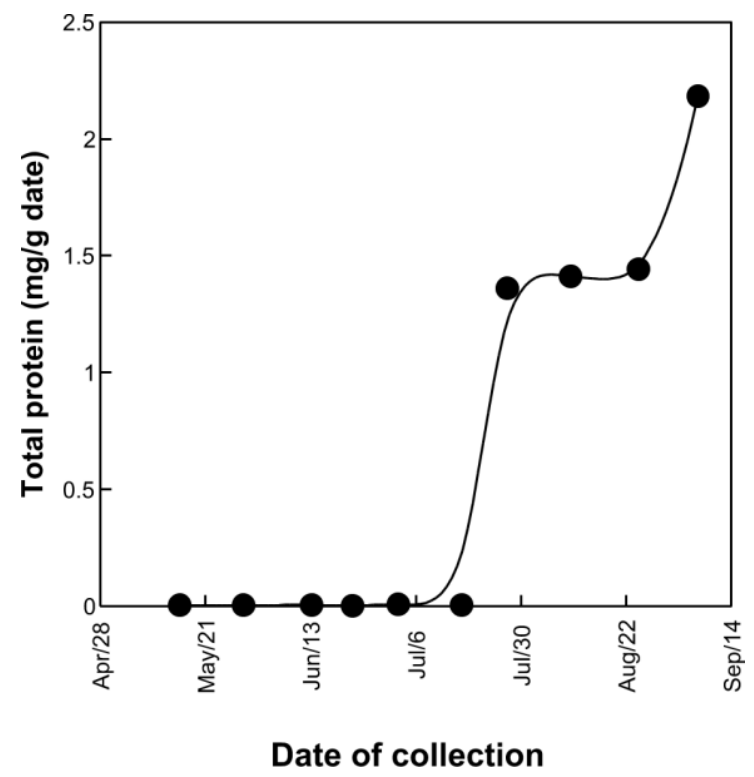

Figure 10: Soluble protein content of khalas fruit at the various stages of ripening. Samples representing the various stages of ripening were extracted with a buffer containing $50 \mathrm{mM}$ sodium acetate $(\mathrm{pH} \mathrm{5.0)}$ and $100 \mathrm{mM} \mathrm{NaCl}$.

\section{Discussion}

The changes in total sugars come out to make changes in reducing sugars, which in 
turn preceded changes in protein content; this suggested that the synthesis of non-reducing sugar preceded the synthesis of reducing sugar. There might be an independent occurrence of the non-reducing sugar via different pathways or enzymes. There was a transient induction of intervase in sullaj that converts sucrose into fructose and glucose due to the decline in the sugar content at the final ripening stage.

The comparison between the total sugars and reducing sugars among the date fruits have been examined, which showed all the varieties of dates have a high content of total sugars in variant form. The similar findings have been reported in the analysis of Assirey (2015) which studied 10 type of date fruit. In the present study, a considerable variation has been observed among the date fruits in terms of their content of non-reducing sugar. Among all the varieties of the date, fruits examined, sukkari has the highest non-reducing sugar content at the rutab stage. The minimal amount of reducing sugar was observed in khalas date throughout the process of ripening.

A study conducted by Eid et al. (2013) reported how the levels of polyphenols in date fruits changes with the cultivar type and the process of ripening. Ajwa, Barni, and Khalas were the varieties of dates considered in this study. It has been observed that the concentration of polyphenols was at the highest level at the early phase of the ripening process. The Ajwa dates were observed to have higher levels of phenols than measured in Barni and Khalas (Eid et al., 2013). The study conducted by Adam et al. (2016) partially relates to the present study as the results obtained showed that PPO activity might be responsible for the browning of date fruits, possibly via oxidation of polyphenols, which are abundant in all date varieties.

\section{Conclusion}

The results have concluded that there was an increased fruit content of soluble proteins, sugars, certain enzymes activities, and certain polyphenols in context to date fruit ripening. Although, most of the cultivars contain almost similar chemical components there are several differences also. The coordination among several enzymes may also influence the ripening or the quality of date fruits; the relative ratio of enzyme activities might be as important as the absolute amount of each enzyme. It is of interest to note that nonreducing sugar content declined as the fruit entered the Tamar stage in all date varieties examined in this study. By contrast, the reducing sugar increased in all date fruits with ripening. This suggested that non- reducing sugars were being hydrolyzed to reducing sugars in date fruits. While the nature of nonreducing sugars present in date fruit was not determined in this study. It was interesting to note that the content of non-reducing sugar declined as the fruit entered Tamar stage in all the date varieties examined in this study. According to the results, the reducing sugar increased in almost all varieties of dates, and this suggested that non-reducing sugar were being hydrolyzed to reducing sugar in date fruits. It suggests that date fruits utilization on an industrial basis must be based on different phenotypical and biochemical features. It directs the future researches to explore the relationship between the date fruits chemical composition and its fruit color, taste and texture. Future studies might be conducted by some microbiological analysis that can assist in finding more about the enzyme activities in dates. Since the study only used two concentrations for BSA standard, therefore, future studies take more concentrations. It has also been highly recommended to improve the handling and harvesting methods (grading, storing and packaging) of dates. Future studies must focus on the microbial analysis and chemical composition of the other kinds of dates found in Saudi Arabia.

\section{Acknowledgements}

The author is very thankful to all the associated personnel in any reference that contributed to/for this research. Further, this research holds no conflict of interest and is not funded through any source.

\section{References}

Adam, I. K., Adam A. A., \& Bello, B. A. (2016). Effect of Polyphenol Oxidase on Browning of Apple and Garden Egg. Dutse Journal of Pure and Applied Sciences (DUJOPAS), 2(2), 177184. 
Agudelo, A., Varela, P., Sanz, T., \& Fiszman, S. (2014). Formulating fruit fillings. Freezing and baking stability of a tapioca starch-pectin mixture model. Food Hydrocolloids, 40, 203213.

Aleid, S. M., Al-Khayri, J. M., \& Al-Bahrany, A. M. (2015). Date palm status and perspective in Saudi Arabia. In Date palm genetic resources and utilization (pp. 49-95). Springer, Dordrecht. Doi: 10.1007/978-94-017-9707-8_3

Al-Jasass, F. M., Siddiq, M., \& Sogi, D. S. (2015). Antioxidants activity and color evaluation of date fruit of selected cultivars commercially available in the United States. Advances in Chemistry, 2015. https://doi.org/10.1155/2015/ 567203

Amira, E. A., Behija, S. E., Beligh, M., Lamia, L., Manel, I., Mohamed, H., \& Lotfi, A. (2012). Effects of the ripening stage on phenolic profile, phytochemical composition and antioxidant activity of date palm fruit. Journal of agricultural and food chemistry, 60(44), 1089610902. Doi: https://doi.org/10.1021/jf302602v

Assirey, E. A. R. (2015). Nutritional composition of fruit of 10 date palm (Phoenix dactylifera L.) cultivars grown in Saudi Arabia. Journal of Taibah University for science, 9(1), 75-79.

Das, S. (2015). Perception of food and nutrition and dietary recommendation in health and disease: focus on Caraka-Susfruta Sam. hita-s. Indian J Hist Sci, 50, 131-47. Doi: 10.16943/ijhs/2015/ v50i1/48116

Eid, N. M., Al-Awadi, B., Vauzour, D., OrunaConcha, M. J., \& Spencer, J. P. (2013). Effect of cultivar type and ripening on the polyphenol content of date palm fruit. Journal of agricultural and food chemistry, 61(10), 24532460. Doi:10.1021/jf303951e

Ghnimi, S., Umer, S., Karim, A., \& Kamal-Eldin, A. (2017). Date fruit (Phoenix dactylifera L.): An underutilized food seeking industrial valorization. NFS Journal, 6, 1-10. https://doi.org/10.1016/j.nfs.2016.12.001

Haider, M. S., Khan, I. A., Jaskani, M. J., Naqvi, S. A., \& Khan, M. M. (2014). Biochemical attributes of dates at three maturation stages. Emirates Journal of Food and Agriculture, 26(11), 953-963. https://doi.org/10.9755/ejfa. v26i11.18980

Li, M., Li, D., Feng, F., Zhang, S., Ma, F., \& Cheng, L. (2016). Proteomic analysis reveals dynamic regulation of fruit development and sugar and acid accumulation in apple. Journal of experimental botany, 67(17), 5145-5157. Doi: 10.1093/jxb/erw277

Mou, W., Li, D., Luo, Z., Mao, L., \& Ying, T. (2015). Transcriptomic Analysis Reveals
Possible Influences of ABA on Secondary Metabolism of Pigments, Flavonoids, and Antioxidants in Tomato Fruit during Ripening. PloS one, 10(6), e0129598. Doi: http://dx.doi.org/10.1371/journal.pone.0129598

Mrabet, A., Rodríguez-Arcos, R., Guillén-Bejarano, R., Chaira, N., Ferchichi, A., \& Jiménez-Araujo, A. (2012). Dietary fiber from Tunisian common date cultivars (Phoenix dactylifera L.): Chemical composition, functional properties, and antioxidant capacity. Journal of agricultural and food chemistry, 60(14), 3658-3664. https://doi.org/10.1021/jf2035934

Nestle, M. (2013). Food politics: How the food industry influences nutrition and health (Vol. 3). Univ of California Press.

Rastegar, S., Rahemi, M., Baghizadeh, A., \& Gholami, M. (2012). Enzyme activity and biochemical changes of three date palm cultivars with different softening pattern during ripening. Food chemistry, 134(3), 1279-1286. Doi:http://dx.doi.org/10.1016/j.foodchem.2012. 02.208

Sahni, T. K., \& Goel, A. (2015). Microbial enzymes with special reference to $\alpha$-amylase. Bio Evol, 2, 19-25.

Saleem, S. A., Baloch, A. K., Baloch, M. K., Baloch, W. A., \& Ghaffoor, A. (2005). Accelerated ripening of Dhakki dates by artificial means: ripening by acetic acid and sodium chloride. Journal of Food Engineering, 70(1), 61-66. Doi: http://dx.doi.org/10.1016/ j.jfoodeng.2004.09.013

Shamim, F., Ali, M. A., Asghar, M., Din, A., Babu, I., \& Yasmin, Z. (2013). Controlled Ripening of Date Palm Fruit and Impact on Quality During Post Harvest Storage. Extensive Journal of Applied Sciences, 1(1), 61-65. URL: http://ejasj.com/wp-ontent/uploads/2014/11/6165.pdf

Sirisena, S., Ng, K., \& Ajlouni, S. (2015). The Emerging Australian Date Palm Industry: Date Fruit Nutritional and Bioactive Compounds and Valuable Processing By-Products. Comprehensive Reviews in Food Science and Food Safety, 14(6), 813-823. Doi: 10.1111/1541-4337.12162

Terasaki, S., Sakurai, N., Kuroki, S., Yamamoto, R., \& Nevins, D. J. (2013). A new descriptive method for fruit firmness changes with various softening patterns of kiwifruit. Postharvest biology and technology, 86, 85-90. Doi: http://dx.doi.org/10.1016/j.postharvbio.2013.06. 009

Tucker, G. A., \& Grierson, D. (2013). Fruit ripening. The biochemistry of plants, 12, 265318. 